\title{
A comparison of sex, morphology, physiology, and behavior of black-capped chickadees trapped using two common capture methods
}

\author{
Sara M Burns ${ }^{1}$, Frances Bonier ${ }^{\text {Corresp. } 1}$ \\ ${ }^{1}$ Department of Biology, Queen's University, Kingston, Ontario, Canada \\ Corresponding Author: Frances Bonier \\ Email address: bonierf@queensu.ca
}

Many biological studies require the capture of individuals for sampling, for example for measurement of morphological or physiological traits, or for marking individuals for later observations. Capture methods employed often vary both within and between studies, and these differing methods could be more or less effective in capture of different individuals based on their morphology or behaviour. If individuals that are prone to capture by the selected method differ with respect to traits of interest, such sampling bias could generate misleading or simply inaccurate results. The selection of capture methods could introduce two different forms of sampling bias, with the individuals that are sampled differing from the population at large or with individuals sampled via one method differing from individuals that could be sampled using a different method. We investigated this latter form of sampling bias by comparing individual birds sampled using two common capture techniques. We caught free-ranging black-capped chickadees (Poecile atricapillus) using walk-in traps baited with seed and mist nets paired with playback of an audio stimulus (conspecific mobbing calls). We measured 18 traits that we expect might vary among birds that are trappable by these differing methods - one that targets birds that are food motivated and potentially less neophobic and another that targets birds that respond readily to a perceived predation risk. We found no differences in the sex, morphology, initial and stress-induced corticosterone concentrations, behavioral response to a novel object, or behavioral response to a predator between individuals captured by these two methods. Individual variation in the behavioral response to a novel object was greater among birds caught by mist nets, suggesting this method might provide a sample that better reflects population-level individual variation. We do not know if the birds caught by these two methods provide a representative sample of the population at large, but can conclude that selection of either of these two common capture methods can similarly sample mean trait values of a population of interest. To accurately assess individual variation, particularly in behavior, mist nets might be preferable.
Peer) reviewing PDF ( 2020:03:46448:1:1:NEW'28 Jul 2020) 
1

2 A comparison of sex, morphology, physiology, and

3 behavior of black-capped chickadees trapped using

4 two common capture methods

5

6 Sara M. Burns ${ }^{1}$ and Frances Bonier ${ }^{1}$

7

$8 \quad{ }^{1}$ Department of Biology, Queen's University, Kingston, Ontario, Canada

9

10 Corresponding Author:

11 Frances Bonier

12116 Barrie St., Queen's University, Department of Biology, Kingston, ON K7L 3N6, Canada

13 Email address: bonierf@queensu.ca

14 
16

17

18

19

20

21

22

23

24

25

26

27

28

29

30

31

32

33

34

35

36

37

38

39

40

41

42

43

44

45

46

47

48

49

50

51

52

53

54

55

\section{Abstract}

Many biological studies require the capture of individuals for sampling, for example for measurement of morphological or physiological traits, or for marking individuals for later observations. Capture methods employed often vary both within and between studies, and these differing methods could be more or less effective in capture of different individuals based on their morphology or behaviour. If individuals that are prone to capture by the selected method differ with respect to traits of interest, such sampling bias could generate misleading or simply inaccurate results. The selection of capture methods could introduce two different forms of sampling bias, with the individuals that are sampled differing from the population at large or with individuals sampled via one method differing from individuals that could be sampled using a different method. We investigated this latter form of sampling bias by comparing individual birds sampled using two common capture techniques. We caught free-ranging black-capped chickadees (Poecile atricapillus) using walk-in traps baited with seed and mist nets paired with playback of an audio stimulus (conspecific mobbing calls). We measured 18 traits that we expect might vary among birds that are trappable by these differing methods - one that targets birds that are food motivated and potentially less neophobic and another that targets birds that respond readily to a perceived predation risk. We found no differences in the sex, morphology, initial and stress-induced corticosterone concentrations, behavioral response to a novel object, or behavioral response to a predator between individuals captured by these two methods. Individual variation in the behavioral response to a novel object was greater among birds caught by mist nets, suggesting this method might provide a sample that better reflects population-level individual variation. We do not know if the birds caught by these two methods provide a representative sample of the population at large, but can conclude that selection of either of these two common capture methods can similarly sample mean trait values of a population of interest. To accurately assess individual variation, particularly in behavior, mist nets might be preferable.

\section{Introduction}

Almost all biological studies require the collection of data from a subset of individuals, from which inferences are made about a broader population. Implicit to this approach is an assumption that the individuals we sample are a random and representative subset of this population of interest (Biro, 2013; Fowler, Cohen \& Jarvis, 2013). However, some of the sampling methods we use in data collection might introduce bias. For example, in studies of freeranging animals, we might inadvertently skew our samples towards individuals that we can capture by a particular method because they exhibit certain behaviors (Garamszegi, Eens \& Török, 2009; Biro, 2013; Stuber et al., 2013; Biro \& Sampson, 2015). These individuals might represent a non-random sample in terms of their life history, morphology, physiology, and/or behavior.

Sampling bias might be introduced by capture method in at least two different ways. First, individuals that are captured might differ from those that are not captured. Second, different capture techniques might more readily trap individuals that differ with respect to their 
56

57

58

59

60

61

62

63

64

65

66

67

68

69

70

71

72

73

74

75

76

77

78

79

80

81

82

83

84

85

86

87

88

89

90

91

92

93

94

95

morphology, physiology, behavior, or other traits. The first form of bias might be driven by traits that influence an individual's propensity to be captured at all (i.e., its trappability). Specifically, individuals that are bolder, more active, and less neophobic might often be over-represented in a sampled population relative to the broader population (Biro \& Dingemanse, 2009). Evidence of this form of capture bias has been found in studies of numerous taxa, including fish (Biro \& Post, 2008; Wilson et al., 2011; Biro \& Sampson, 2104), lizards (Carter et al., 2012), mammals

(Tuyttens et al., 1999; Réale et al., 2000; Boon, Réale \& Boutin, 2008), birds (Garamszegi, Eens \& Török, 2009; Stuber et al., 2013; Camacho, Canal \& Potti, 2017), and invertebrates (Niemelä, Lattenkamp \& Dingemanse, 2015). In some studies, trappability itself has been used as a measure of personality, with willingness to enter a trap interpreted as an indicator of propensity for risk taking (e.g., Réale et al., 2000; Boon, Réale \& Boutin, 2008, but see Brehm \& Mortelliti, 2018).

We have good evidence that probability of capture is not equal for all individuals in a population, and that the individuals that can be captured sometimes differ from those that cannot (examples reviewed above). However, when studies require the capture of individuals, for instance to measure morphological or physiological traits, we must implement some method of capture. Decisions about which capture method to use are often made based on convenience or convention, without knowledge of whether or not different capture methods select for different individuals. For example, field ornithologists commonly employ several capture methods, such as mist nets, food-baited traps, or nest-box traps (Elekonich \& Wingfield, 2000; McGlothlin et al., 2008; Bonier, Moore \& Robertson, 2011; DeVries, Winters \& Jawor, 2012), sometimes without evaluating if traits of interest differ among individuals captured by the selected method(s) versus alternative available methods. Prior studies have provided ample evidence that capture methods can differ in effectiveness, as well as the species, age, sex, size, and condition of captured individuals (Boonstra \& Krebs, 1978; Weatherhead \& Greenwood, 1981; Spence \& Niemelä, 1994; Bauchau \& van Noordwijk, 1995; Gorney, Clark \& Yom-Tov, 1999; Anthony et al., 2005; Burger et al., 2009; Stokes, 2013). Fewer studies have compared personality-related traits of individuals caught by different methods (Wilson et al., 2011; Michelangeli, Wong \& Chapple, 2016). To our knowledge, all prior studies that have compared endocrine traits of individuals caught by different methods have tested for the effects of capture methods on hormone concentrations (e.g., due to initiation of a stress response), rather than testing for endocrine trait sampling bias due to capture method (Fletcher \& Boonstra, 2006; Lynn \& Porter, 2008; Angelier et al., 2010).

The propensity to be trapped by certain capture methods can be influenced by a number of individual traits, such as morphology, sex, physiology, and behavior. For example, some obvious differences in morphology, such as body size, could bias which individuals are captured because of trap design (e.g., size-selective trapping methods). An individual's condition and prospects for future reproduction might influence risk taking behaviour, with individuals with greater future fitness prospects being more risk averse, and individuals in poor condition being more willing to take risks, particularly to access food (Clark, 1994; Killen, Marras \& McKenzie, 
2011; Nicolaus et al., 2012). Sex can also influence behavior in many contexts, including territoriality, offspring defense, and foraging (Regelmann \& Curio, 1986; Clarke et al., 1998; Ruckstuhl, 1998; Smith, Bronstein \& Papaj, 2019), and thus trappability might also differ among males and females. Endocrine traits (e.g., circulating concentrations, responsiveness of endocrine axes, etc.) can vary considerably among individuals often in ways that correlate with, and potentially also regulate, individual behavior or personality (Koolhaaas et al., 1999; Cockrem, 2007; Williams, 2008; Carere, Caramaschi \& Fawcett, 2010; Baugh et al., 2013; Cockrem, 2013). These endocrine differences might be associated with individual variation in trappability. For example, glucocorticoid hormones differ with respect to, and regulate, an individual's metabolic rate, foraging behavior, and life history stage (Landys, Ramenofsky \& Wingfield, 2006; Lohmus, Sundström \& Moore, 2006; Wada, 2008; Wack et al., 2013; Jimeno, Hau \& Verhulst, 2017), and thus might differ among individuals caught by methods using food versus broadcast of sounds (e.g., conspecific song or mobbing calls) as lures. Hormone concentrations can also vary consistently among individuals (Schoenemann \& Bonier, 2018), and can be associated with behavioral traits such as risk-taking, boldness, and exploratory behavior (Koolhaas et al., 1999; Martins et al., 2007; Baugh et al., 2012; Baugh et al., 2013), all of which could influence an individual's propensity to approach or investigate a trap. Finally, personality, by definition, predicts behavior across contexts, and might be one of the most important drivers of sampling bias (Biro \& Dingemanse, 2009; Garamszegi, Eens \& Török, 2009), with different traps potentially selecting for individuals that exhibit different behaviors.

Because of the variety of factors that could contribute to sampling bias, its occurrence could have a large impact on the outcomes of many biological studies, in some cases even resulting in skewed or inaccurate conclusions. Here, we test the hypothesis that capture method influences which individuals are sampled in wild populations by comparing multiple traits of free-ranging black-capped chickadees (Poecile atricapillus) captured using two different and common capture techniques: walk-in traps baited with food and mist-nets paired with broadcast of an audio recording of a conspecific anti-predator response.

We measured a suite of 18 traits including genetic sex, initial and capture stress-induced corticosterone, morphology (size, mass, fat, body condition), and foraging behavior at baseline and in the presence of two different stimuli (cues of predator presence and a novel object). We chose the two capture methods based on their routine use in field ornithological studies, and because of their potential to nonrandomly capture birds that differ from each other. Walk-in traps require that individuals enter a wire cage to forage, and so might select for more food motivated and less neophobic individuals, whereas mist nets are designed to be practically invisible to birds (with more or less success depending on setting and species), and so they select for individuals responsive to the paired lure(s), if any is used. In this study, pairing mist nets with playback of conspecific mobbing of a predator of adult chickadees should select for bolder individuals that are more responsive to perceived predation risks. As such, we predicted that individuals caught by these two methods might differ with respect to sex, morphology, physiology, and/or behavior. 


\section{Materials \& Methods}

\section{Study system}

138 We sampled black-capped chickadees at 10 different sites on properties of the Queen's

139 University Biological Station (QUBS; near Elgin, Ontario; 4434'N, 76 $19^{\prime} \mathrm{W}$ ) from October

140 through December of 2014. Black-capped chickadees form flocks generally comprising 3-12

141 individuals and occupy a relatively stable winter territory (Foote et al., 2010), permitting

142 sampling of multiple individuals at one site. Chickadees readily come in to human-provided food

143 sources, such as bird feeders, and so can be captured with food-baited traps. Finally, black-

144 capped chickadees and their relatives in the family Paridae (e.g., blue tits and great tits) are a

145 common subject of a diverse array of biological studies involving capture and sampling.

146

147

148

149

150

151

152

153

154

155

\section{Capture and sampling}

We captured birds between 0700 and 1300, starting no earlier than 1 hour after sunrise to minimize the influence of diel variation in circulating hormone concentrations. We trapped at a given site for no more than 112 minutes within this time window (mean time from capture of first to last bird at a given site $=86$ minutes). We used both capture methods at each site: walk-in (Potter) traps baited with black oil sunflower seeds and mist nets paired with playback of an audio recording of chickadees mobbing an eastern screech-owl (Megascops asio). Eastern screech-owls are a predator of adult black-capped chickadees, and their presence elicits an antipredator behavioral response (Shedd, 1983; Foote et al., 2010). We put baited walk-in traps on platforms ( $\sim 1.5 \mathrm{~m}$ off the ground) out at sites with their doors secured open for several days before sampling (mean $=13$ days; range $=3-24$ days) to allow birds to locate the seed and become accustomed to entering the traps to forage. This acclimation period should reduce the role of individual variation in neophobia in capture by this method. We sampled at nine sites on the same day, alternating the order of which capture method we used first between sites, and waiting a minimum of 30 minutes after capture of the last individual by the first method before beginning use of the second technique at the same site. At one site, we mist netted on the day after trapping via walk-in trap because of deteriorating weather conditions on the first day. Results do not differ if data from this site are excluded. When mist netting, we immediately turned off playback once an individual became entangled in the net. Playback was resumed only when one person could watch the net again to stop playback and extract the next captured bird. Audio playback never extended beyond 10 minutes of uninterrupted play (mean $=198 \mathrm{~s}$; range $=$ 10-600s). Because chickadee flocks typically consist of 6-8 individuals (Smith, 1991), we limited sampling to the first three birds captured by each method, to ensure both methods could be used on each flock. This approach should also maximize our chance of detecting differences among birds caught by the two methods, if they exist, based on the assumption that the first few

173 individuals vary in their trappability by these methods). Trapping sites were spaced to minimize

174 flock territory overlap (mean distance $=8.8 \mathrm{~km}$; range $=285 \mathrm{~m}-21 \mathrm{~km}$ ). We did not capture any 
175 individuals at more than one trapping site. We also did not capture any individual by more than

176

177

178

179

180

181

182

183

184

185

186

187

188

189

190

191

192

193

194

195

196

197

198

199

200

201

202

203

204

205

206

207

208

209

210

211

212

213

214

one method, within each site.

Upon capture, we collected an initial blood sample into a heparinized microcapillary tube via puncture of the brachial vein (maximum $70 \mu \mathrm{L}$ ) with a 26-gauge needle as quickly as possible after the bird entered either capture device (i.e., the time when the door closed on the walk-in trap or the bird became entangled in the mist net). Three minutes post-capture is commonly used as a cut-off for measurement of baseline corticosterone (the primary glucocorticoid in birds) (Romero \& Reed, 2005); however, we found a linear increase in $\ln$ transformed corticosterone with sampling time (Fig. S1; linear model: $\mathrm{N}=52, \beta=0.006 \pm 0.001$, $\mathrm{p}<0.001)$. Because of this relationship with sampling time, and differences in sampling time between methods (mean sampling time: walk-in trap $=135.2 \mathrm{~s}$, mist net $=162.1 \mathrm{~s}$; $\mathrm{t}$-test: $\mathrm{t}=2.27$, $\mathrm{df}=44.11, \mathrm{p}=0.03$ ), we used the residuals of the linear regression of $1 \mathrm{n}$-transformed corticosterone on sampling time including samples collected past the 3-minute time period (mean sample time $=148.12 \mathrm{~s}$, range $=55-275 \mathrm{~s}$ ) in subsequent analyses. Results do not differ if the 10 samples collected beyond 3 minutes post-capture are excluded from analyses, or if raw corticosterone concentrations, uncorrected for the relationship with sampling time, are used. The amount of time elapsed from initiating the capture attempt to the time the bird was captured was unrelated to corticosterone (linear model: $\beta=-7.34 * 10-5 \pm 7.79 * 10-5, p=0.35$ ), suggesting no effect of duration of disturbance due to our presence or audio playback at the trapping site.

We collected morphological measurements from each bird, including flattened wing chord using a wing ruler $( \pm 0.5 \mathrm{~mm})$, tarsus length with calipers $( \pm 0.1 \mathrm{~mm})$, and body mass with a Pesola spring scale ( $\pm 0.5 \mathrm{~g})$. We estimated a fat score for each individual by observing the amount of visible fat deposits in the furculum (inter-clavicular depression) using a scale from 0 (no visible fat) to 5 (excessive fat deposits) (Krementz \& Pendleton, 1990). We calculated a scaled mass index (SMI) to estimate body condition of each individual using the slope of the least-squares regression of ln-transformed body mass (grams) on ln-transformed wing length $(\mathrm{mm})$. We used wing length instead of tarsus length because it was more strongly correlated with body mass. We followed the Thorpe-Lleonart equation to estimate SMI: individual body mass * (population mean wing length/ individual wing length)^slope (Peig \& Green, 2009). In this equation, the 'slope' exponent is the scaled major axis slope, which is estimated as the slope from the least-squares regression divided by the correlation between body mass and wing length (Peig \& Green, 2009). In our data, the correlation between body mass and wing length was 0.70 , and the SMA slope was 2.12. The population mean wing length was $66.16 \mathrm{~mm}$.

We fit each bird with a uniquely numbered Canadian Wildlife Service aluminum band, a plastic colored leg band (Avinet, Dryden, NY), and a passive integrative transponder (PIT) leg band (Eccel Technology, Leicester, UK). After we had obtained all measurements and banded birds, we placed them in an opaque, breathable cloth bag until 30 minutes after capture. We then collected a second blood sample for measurement of capture stress-induced corticosterone levels using the same collection method as described above. We failed to collect sufficient blood to measure initial or stress-induced corticosterone for a few birds ( 3 initial, 2 stress-induced). We

PeerJ reviewing PDF | (2020:03:46448:1:1:NEW 28 Jul 2020) 
215 kept all blood samples cool by storing them on ice for transport to the laboratory at Queen's

216 University. All capture and handling methods were approved by the Queen's University Animal

217 Care Committee (protocol 2013-057) and banding was conducted under a Canadian Wildlife

218 Service banding permit (permit 10771).

219

220

\section{Behavioral assays}

221

We completed all behavioral trials during December 2014, between 0800-1200, a

222 minimum of 22 days after capture (mean $=35$ days; range $=22-49$ days). We used radio

223

224 frequency identification (RFID) readers mounted to bird feeders (Bird Feeder Reader Meter, IB Technology, Buckinghamshire, UK) at the feeding stations that had been established at the time

225 of capture at each site. Birds at each site were allowed to habituate to the RFID feeder readers for

226 a minimum of two full days ( mean $=6$; range $=2-8$ ). We used RFID readers to measure activity

227

228 at the feeder for three separate segments of the behavioral trials (details below). We set readers to record individual PIT tag numbers, time, and date twice per second. We carried out trials over

229 three consecutive days, with different segments of data collection occurring on separate days: a

230

231

232 pre-trial control period, response to a predator model, and response to a novel object, with the type of stimulus (model predator or novel object) presented on the second or third days, alternating order between sites. Each trial lasted 2 hours and all trials occurred at the same time

233 of day within sites, allowing for direct comparison of behavior among trials. To assay risk-taking in response to a predation threat, we exposed each flock of chickadees to a small owl model paired with playback of an audio recording of an eastern screech-owl's call. We used five different screech-owl recordings, all obtained from the Macaulay Library at the Cornell Lab of Ornithology. We played each audio recording from a FoxPro Scorpion X1B speaker (FOXPRO Inc., Lewistown, PA) programmed to play back the audio stimulus (5min) interspersed with segments of silence of varying duration (range 3-13min). Each site received the same program of audio stimulus and silence, but we varied which of the five recordings was used. We checked volumes of each call with a sound meter to ensure all were played at 80-90 decibels at a distance of 1 meter. This range reflects natural variation of screech-owl vocalizations as captured within the recordings we used, and playback volume was similarly varied across all sites. At each site, we placed the model predator and speaker in a tree 1-1.5m from the RFID feeder reader. We then left the area for 2 hours and used the RFID $\log$ to determine number of visits to the feeder in the presence of the predator stimulus. To assay willingness to visit the feeder in the presence of a novel object, we placed a red plastic drinking cup directly on top of the RFID feeders and left it in place for 2 hours, again recording visits from the RFID log. Some of the initially captured birds were not recorded at RFID feeders during behavioral trials. Sample sizes are provided for each measurement (Table 1).

We assessed response to a predator and a novel object by tallying the total number of trips to the feeder and the mean duration of time spent at the feeder during each trip (total duration of time detected at the feeder in seconds, divided by number of trips) for each individual during each two-hour trial (pre-trial control, predator trial, novel object trial). If an individual 
255

256

257

258

259

260

261

262

263

264

265

266

267

268

269

270

271

272

273

274

275

276

277

278

279

280

281

282

283

284

285

286

287

288

289

290

291

292

293

294

was detected at the feeder during some but not all of the trials, we assigned them a value of zero for both behaviors (number and mean duration of visits)for the trials they when they were not detected, but we excluded individuals that were never detected at the feeder during any of the trials from the analyses. We analyzed foraging behavior using both raw values for each individual (number and mean duration of visits to the feeder during each trial) and by calculating the change in behavior relative to the control trial (i.e., [number or duration of visits during predator or novel object exposure - number or duration of visits during pre-trial control] / number or duration of visits during pre-trial control). With this calculation, a negative value represents a reduction of trips to or duration of time spent at the feeder, a positive value represents an increase, and a zero reflects no change. The magnitude of the value reflects the scale of the change relative to behavior in the absence of the stimuli. Importantly, with this calculation of change in behavior, values cannot be lower than -1, which represents individuals that were present during the pre-trial control but did not visit the feeder during the predator or novel object trial (number/duration of feeder visits $=0$ ). One individual that visited the feeders during the novel object trial was excluded from these analyses because it did not visit the feeder during the pre-trial control (or predator trial), and so a scaled change in behavior could not be calculated. Results do not differ if the response to the stimulus is calculated as a simple difference without scaling by the control value (e.g., stimulus behavior - pre-trial control behavior). We did not assess repeatability of behaviors within individuals and so do not assume that foraging behaviors during the various trials reflect individual variation in personality. Previous estimates suggest that activity, response to novel objects, and exploratory behaviors have low to moderate repeatability in black-capped chickadees (Devost et al., 2016) and other bird species (van Oers et al., 2004; Bell, Hankison \& Laskowski, 2009; Garamszeji et al., 2015; Audet, Ducatez \& Lefebvre, 2016; Holtmann, Lagisz \& Nakagawa, 2017).

\section{Hormone assay}

We centrifuged blood samples for 5 minutes at $6000 \mathrm{rpm}$ within 6 hours of collection, which is well within the timing during which hormone concentrations remain stable at cool temperatures (Khonmee et al., 2019). We then preserved plasma and red blood cells separately at $-20^{\circ} \mathrm{C}$ until further processing. We measured total plasma corticosterone using an enzyme immunoassay (EIA) with a detection limit of approximately $30 \mathrm{pg} / \mathrm{mL}$ (Cayman Chemical Co., Ann Arbor, MI, Lot No. 0457099). No samples fell below this detection limit. Prior to assaying experimental samples, we validated the assay for use in this species by assaying a serial dilution of pooled plasma collected from multiple black-capped chickadees, sampled during the same life history stage, as well as a serial dilution of pooled plasma that was spiked with corticosterone to increase concentration by $10 \mathrm{ng} / \mathrm{ml}$. Both serial dilution curves ran parallel to the assay standard curve. We assayed $7.5 \mu \mathrm{L}$ of each plasma sample from focal birds in duplicate after dilution (1:16, using steroid buffer) on three plates following supplier instructions. We ran eight knownconcentration standards, also in duplicate, on each plate to determine intra and inter-plate variation. The coefficient of variation based on these replicate standards was $5.3 \%$ between 
295

296

297

298

299

300

301

302

303

304

305

306

307

308

309

310

311

312

313

314

315

316

317

318

319

320

321

322

323

324

325

326

327

328

329

330

331

332

333

334

plates and averaged 3.0\% within plates. Baseline corticosterone concentrations in this population during the non-breeding season have been estimated to be somewhat repeatable $(r=0.26$; Montreuil-Spencer et al., 2019). We have not estimated repeatability of stress-induced corticosterone concentrations for this population, but they are generally more repeatable than baseline concentrations (Schoenemann \& Bonier, 2018). As such, individual variation in corticosterone concentrations is expected to reflect both by flexible and consistent differences among individuals.

\section{Molecular sexing}

To differentiate male and female black-capped chickadees, which are not highly dimorphic in morphology or plumage, particularly outside of breeding, we extracted DNA from red blood cells using Qiagen DNeasy Blood and Tissue Kits following the supplier's protocol for nucleated blood cells (Qiagen Inc., Toronto, Ontario, Canada). We used molecular sexing techniques as described by Griffiths et al. (1998). After separation of PCR products by electrophoresis, we identified females by the presence of two bands (WZ) and males by the presence of a single band (ZZ). As quality control measures, we included samples from birds of known sex as well as negative controls in all PCRs, which always produced expected results.

\section{Statistical analysis}

We completed all analyses using $\mathrm{R}$ (version 4.0.0), and all raw data and code for the main analysis have been uploaded to Open Science Framework (available at: https://osf.io/zsjme/). To determine if individuals captured by the two methods differ for any of the traits we measured, we used conditional inference tree analysis using the ctree function in the package partykit (Hothorn $\&$ Zeileis, 2015). Conditional inference tree analyses are a form of non-parametric regression tree analysis that uses recursive partitioning to identify factors that predict variation in a response variable (Hothorn, Hornik \& Zeileis, 2006, Hothorn \& Zeileis, 2015). We included all of the trait measurements as candidate predictor variables (Table 1) and method of capture (walk-in trap or mist net) as the response variable. Results do not differ if we instead analyze each trait separately as a response variable in a linear mixed-effect model with capture method as the sole fixed effect and capture site, order of use of capture methods, and/or order of stimulus presentation (for behavioral data) as random effects. Conditional inference tree and other decision tree approaches are increasingly being used in ecological research (e.g., Johnstone, Lill \& Reina, 2014; Maslo et al, 2016; Burke et al., 2020; d'Entrement et al., 2020), and can be preferable to traditional regression methods as they can allow for a more conservative, refined, and holistic approach to identifying differences among groups (Cutler et al., 2007; Müller, Schröder \& Müller, 2009, Blank \& Blaustein, 2014). Conditional inference trees are also powerful because of their ability to simultaneously assess categorical and continuous variables (including data with non-normal distributions) and to accommodate missing values (Hothorn, Hornik \& Zeileis, 2006).

We conducted a follow-up analysis on a subset of our data to determine if the birds that were most readily caught by each method differed from each other for any of the traits that we 
335

336

337

338

339

340

341

342

343

344

345

346

347

348

349

350

351

352

353

354

355

356

357

358

359

360

361

362

363

364

365

366

367

368

369

370

371

372

373

374

measured. For this analysis, we repeated the conditional inference tree analyses as described above, but limited to the first three individuals caught at each site, based on the assumption that these first-caught birds were the most trappable. This follow-up analysis suffers from the limitations of a reduced sample size $(\mathrm{N}=30)$ and a lack of pairing of methods within sites, but could be informative, particularly if results differed from those of our main analysis.

Some capture methods might select for a subset of the individuals captured by other methods with a narrower range of trait values, which could result in similar means but different variances among groups. As such, in addition to analyses of mean trait values, we also compared variances among individuals caught by the two capture methods using separate modified Levene's tests of homogeneity of variances from the trait median, which is robust to departures from normality (Carroll \& Schneider, 1985).

\section{Results}

We captured a total of 55 birds at 10 different sites: 28 in mist nets and 27 in walk-in traps. Mean time from initiating the capture effort to capture of birds did not differ between the two methods, although it tended to be faster for walk-in traps (walk-in trap $=9.3 \pm 1.7 \mathrm{~min}$ [mean \pm SE elapsed time], $N=27$; mist nets $=15.3 \pm 3.0 \mathrm{~min}, N=28 ; t=1.68, \mathrm{df}=53, p=0.10$ ). Mean time from initiating the capture effort to capture of birds also did not differ with the order of method used at each site $\left(1^{\text {st }}\right.$ method $=12.4 \pm 2.4 \mathrm{~min}, N=30 ; 2^{\text {nd }} \operatorname{method}=12.3 \pm 2.8 \mathrm{~min}, N=$ $25 ; t=0.03, \mathrm{df}=53, p=0.98)$. We collected behavioral data from 40 of the 55 PIT-tagged individuals.

Individuals caught by walk-in traps and mist nets did not differ in sex (16F, $12 \mathrm{M}$ mist net; 12F, 15M walk-in trap) or any of the morphological (Fig. 1), endocrine (Fig. 2), or behavioral (Fig. 3) traits we measured. None of the traits were identified as covariates of capture method (conditional inference tree analysis, all $\mathrm{p}>0.24$; Table 1). Results were similar when we repeated analyses on only the first three individuals captured at each site, with even less evidence for differences among birds caught by the two methods (conditional inference tree analysis, all $\mathrm{p}$ $>0.72$; Table S1).

Trait variances from the median were similar for endocrine traits (Fig. 2) and for foraging behavior during the different trials (modified Levene's test, all $\mathrm{p}>0.08$; Table 1). Among morphological traits (Fig. 1), there was some evidence of greater variance in fat score among birds caught in walk-in traps relative to mist-netted birds $(\mathrm{F}=4.18, \mathrm{df}=1, \mathrm{p}=0.05)$, but variances for all other morphological traits were similar (all $p>0.38$ ). Variances of changes in rates and duration of visits to the RFID feeder during the predator trial were similar among birds caught by the two capture methods (Fig. 3A \& C; all p > 0.30). Behavioral responses to the novel object trial were more variable among birds that were mist-netted relative to those caught in walk-in traps in terms of change in number of trips to the feeder (Fig $3 \mathrm{~B} ; \mathrm{F}=9.56$, $\mathrm{df}=1, \mathrm{p}=$ 0.004 ), but the variances of change in mean duration of trips was similar among groups (Fig 3D; $\mathrm{F}=0.78, \mathrm{df}=1, \mathrm{p}=0.38)$. 


\section{Discussion}

$376 \quad$ Using different capture methods has the potential to introduce sampling bias that could 377 affect study outcomes. Here, we compared multiple traits of black-capped chickadees caught 378 using two common capture techniques: mist nets paired with playback of an audio stimulus and 379 walk-in traps baited with seed. The range of traits that we measured encompasses many of the 380 traits that we expect to relate to trappability by these two methods. Despite this, we did not find

381

382

383

384

385

386

387

388

389

390

391

392

393

394

395

396

397

398

399

400

401

402

403

404

405

406

407

408

409

410

411

412

413

414 evidence of differences in the sex, morphology (Fig. 1), corticosterone concentrations (Fig. 2), or behavior (Fig. 3) of individuals captured by the two methods. Although mean trait values did not provide evidence of capture bias, trait variances differed for one morphological measure (fat score, Fig. 1E) and one estimate of behavioral response to a novel object (Fig 3B).

We cannot assess the degree to which our sample of captured birds represents the broader population. Bias between individuals that are captured compared to those that are not has been the focus of several studies and reviews (Biro \& Dingemanse, 2009; Garamszegi, Eens \& Török, 2009; Biro, 2013; Stuber et al., 2013; Biro \& Sampson, 2015; Simons et al., 2015; Camacho, Canal \& Potti, 2017), and represents a potential limitation for studies that require capture. Birds caught by both methods could be those in the population that generally exhibit higher levels of risk-taking, which has been found to predict trappability in other species (Garamszegi, Eens \& Török, 2009; Gabriel \& Black, 2010). We expected that bolder birds might approach the predator and conspecific mobbing cues that we paired with the mist nets, whereas more food motivated and less neophobic birds might enter the walk-in trap (although the habituation period we provided should reduce the role of neophobia). Depending on how they are defined and measured, boldness or aggression are sometimes correlated with neophobia, with bolder and more aggressive individuals also being less neophobic (Drent, Verbeek \& Boon, 1996; Koolhaas et al., 1999; Sih, Bell \& Johnson, 2004; but see, Audet, Ducatez \& Lefebvre, 2016), but the relationship between boldness and neophobia is complex, variable, and dependent on context (Réale et al., 2007; Greggor, Thornton \& Clayton, 2015; Biondi et al., 2020). Evidence in blackcapped chickadees does not point to correlations between several personality-related traits, nor a relationship between those traits and social dominance (Devost et al., 2016), although subordinate chickadees exhibit higher risk-taking behavior than dominants in some contexts, including responses to predators and during foraging (Zanette \& Ratcliffe, 1994; Ratcliffe, Mennill \& Schubert 2007). Both capture methods could have targeted birds that are bolder, less risk averse, and less neophobic than birds that were not caught.

Although we did not identify any differences in mean trait values among birds captured in mist nets and walk-in traps, they could differ in ways that we did not measure. One important aspect of flocking species like the black-capped chickadee is their dominance hierarchy, which we did not assess. Individual differences in social rank can influence risk-taking behavior (Schneider, 1984; Hegner, 1985; Zanette \& Ratcliffe, 1994; Ratcliffe, Mennill \& Schubert 2007; An et al., 2011), and so could affect both trappability and response to the model predator or novel object. If there were differences in dominance status between birds captured by the two techniques, we would expect to have detected differences in sex, morphology, body condition, or 
415 behavior, because dominance is often associated with these traits (Ficken, Weise \& Popp, 1990; 416 Smith, 1991; van Oort et al., 2007; Ratcliffe, Mennill \& Schubert 2007; Fox et al., 2009; but see 417 Devost et al., 2016).

418 We found a large degree of individual variation in behavioral responses to the two stimuli, most notably among mist-netted birds in response to the novel object (Fig. 3B), although mean responses did not differ. The difference in variances that we saw suggest that mist nets might capture a broader range of birds, perhaps better representing true population-level

422

423

424

425

426

427

428

429

430

431

432

433

434

435

436

437

438

439

440

441

442

443

444

445

446

447

448

449

450

451

452

453

454 individual variation in behavior. Individuals might change, or not change, their behavior in response to the stimuli we presented for several reasons. In chickadees, we expect dominance hierarchies could influence the direction of response to the stimuli, with lower-ranked individuals being more likely to come in to the feeders during stimulus presentation, while dominants are avoiding the perceived threat (Ficken, Weise \& Popp, 1990; Zanette \& Ratcliffe, 1994; Ratcliffe, Mennill \& Schubert 2007). In contrast, in the absence of these stimuli, subordinates might have their access to the feeder limited by dominants during the control period (Ficken, Weise \& Popp, 1990; Ratcliffe, Mennill \& Schubert 2007). Interestingly, six individuals, all caught in mist nets, more than doubled their visits to the feeder in the presence of the novel object, relative to the control period (scaled change in number of trips $\geq 1$ ), which drives the difference in variances that we found (Fig. 3B). These six individuals might have been subordinates that were excluded from the feeder during the control trial and took advantage of having greater opportunity to forage during the novel object trial, when dominants might have perceived the risk of foraging as too high. If differences in dominance status do explain this difference, this suggests that subordinates are less likely to be captured in walk-in traps than in mist nets. In contrast, five individuals (two caught in walk-in traps, three in mist nets) visited the feeder more than twice as often during the predator presentation as during the control period (Fig. 3A), which does not agree with a dominance hierarchy related interpretation. An additional implication of the high degree of variation we found in behavioral responses is that it reduces our power to detect small differences among the capture method groups, particularly given our relatively small sample sizes.

Our method of data collection cannot distinguish among reasons for individuals' visits to the feeder. Chickadees mob predators by landing close to them and alarm calling (Shedd, 1983; Smith, 1991). We could not determine if birds perched on the RFID feeder as part of a mobbing response, to investigate the stimulus, to forage, or for some other reason. Despite these limitations in interpreting the behavioral data, we can conclude that mean frequencies and durations of visits to the feeder and mean changes in response to the stimuli did not differ among individuals caught by the two methods, although variances differed for one behavioral measure. Without further information, we cannot conclude that risk aversion does not differ among birds caught by the two methods. Increasing sample size, as well as pairing direct observations and data on dominance status with automated techniques would allow for more refined and robust assessments of individual behavior and potential capture bias. 


\section{Conclusions}

456 Experimental design is one of the most important components of any research effort, and 457 choosing appropriate capture methods should be a priority. The type of capture techniques we 458 use in studies of wild birds often depends on convention, logistics, the behavior of our study 459 species, and the focal research question. All capture methods have the potential to introduce bias 460 into our data. We have shown here that the use of either of two common capture methods - food461 baited walk-in traps and mist nets paired with audio playback - do not introduce bias with 462 respect to the sex, morphology, corticosterone concentrations, and, to some extent, behavior of 463 black-capped chickadees. For one metric, individual variation in behavior was greater among 464 birds caught by mist nets, suggesting this method might provide a sample that better reflects 465 population-level individual variation. We expect these findings should apply to other similar

466

467

468

469

470

471

472

473

474

475

476

477

478

479

480

481

482

483

484

485

486

487

488

489

490

491 492 songbirds, providing some reassurance that, when a study requires capture, either of these methods can be employed to similarly sample a population of interest when mean trait values are of primary interest; however, when individual variation is important to a research aim, mist nets may be preferable.

\section{Acknowledgements}

We acknowledge the Queen's University Biological Station for providing access to the properties where we conducted this research. The following recordings from the Macaulay Library at the Cornell Lab of Ornithology were used: Megascops asio 20424, 20425, 20426, 20427, 61814. We thank K. Otter, P. Biro, and R. Curry for their constructive feedback as reviewers of an earlier version of the manuscript.

\section{References}

An, Y. S., Kriengwatana, B., Newman, A. E., MacDougall-Shackleton, E. A., \& MacDougallShackleton, S. A. (2011). Social rank, neophobia and observational learning in black-capped chickadees. Behaviour, 148(1), 55-69.

Angelier, F., Tonra, C. M., Holberton, R. L., \& Marra, P. P. (2010). How to capture wild passerine species to study baseline corticosterone levels. Journal of Ornithology, 151(2), 415422.

Anthony, N. M., Ribic, C. A., Bautz, R., \& Garland Jr, T. (2005). Comparative effectiveness of Longworth and Sherman live traps. Wildlife Society Bulletin, 33(3), 1018-1026.

Audet, J. N., Ducatez, S., \& Lefebvre, L. (2016). The town bird and the country bird: problem solving and immunocompetence vary with urbanization. Behavioral Ecology, 27(2), 637-644. 
493 Bauchau, V., \& Van Noordwijk, A. J. (1995). Comparison of survival estimates obtained from 494 three different methods of recapture in the same population of the great tit. Journal of Applied 495 Statistics, 22(5-6), 1031-1038.

496

497

498

499

500

501

502

503

504

505

506

507

508

509

510

511

512

513

514

515

516

517

518

519

520

521

522

523

524

525

526

527

528

529

530

531

532

Baugh, A. T., Schaper, S. V., Hau, M., Cockrem, J. F., de Goede, P., \& van Oers, K. (2012). Corticosterone responses differ between lines of great tits (Parus major) selected for divergent personalities. General and Comparative Endocrinology, 175(3), 488-494.

Baugh, A. T., van Oers, K., Naguib, M., \& Hau, M. (2013). Initial reactivity and magnitude of the acute stress response associated with personality in wild great tits (Parus major). General and Comparative Endocrinology, 189, 96-104.

Bell, A. M., Hankison, S. J., \& Laskowski, K. L. (2009). The repeatability of behaviour: a metaanalysis. Animal Behaviour, 77(4), 771-783.

Biondi, L. M., Fuentes, G. M., Córdoba, R. S., Bó, M. S., Cavalli, M., Paterlini, C. A., Castano M. V., \& García, G. O. (2020). Variation in boldness and novelty response between rural and urban predatory birds: The Chimango Caracara, Milvago chimango as study case. Behavioural Processes, 173, 104064.

Biro, P. A. (2013). Are most samples of animals systematically biased? Consistent individual trait differences bias samples despite random sampling. Oecologia, 171(2), 339-345.

Biro, P. A., \& Dingemanse, N. J. (2009). Sampling bias resulting from animal personality. Trends in Ecology and Evolution, 24(2), 66-67.

Biro, P. A., \& Post, J. R. (2008). Rapid depletion of genotypes with fast growth and bold personality traits from harvested fish populations. Proceedings of the National Academy of Sciences, 105(8), 2919-2922.

Biro, P. A., \& Sampson, P. (2015). Fishing directly selects on growth rate via behaviour: implications of growth-selection that is independent of size. Proceedings of the Royal Society B: Biological Sciences, 282(1802), 20142283.

Blank, L., \& Blaustein, L. (2014). A multi-scale analysis of breeding site characteristics of the endangered fire salamander (Salamandra infraimmaculata) at its extreme southern range limit. Hydrobiologia, 726(1), 229-244.

Bonier, F., Moore, I. T., \& Robertson, R. J. (2011). The stress of parenthood? Increased glucocorticoids in birds with experimentally enlarged broods. Biology letters, 7(6), 944-946.

PeerJ reviewing PDF | (2020:03:46448:1:1:NEW 28 Jul 2020) 
533

534

535

536

537

538

539

540

541

542

543

544

545

546

547

548

549

550

551

552

553

554

555

556

557

558

559

560

561

562

563

564

565

566

567

568

569

570

571

572

Boon, A. K., Réale, D., \& Boutin, S. (2008). Personality, habitat use, and their consequences for survival in North American red squirrels Tamiasciurus hudsonicus. Oikos, 117(9), 1321-1328.

Boonstra, R., \& Krebs, C. J. (1978). Pitfall trapping of Microtus townsendii. Journal of Mammalogy, 59(1), 136-148.

Brehm, A. M., \& Mortelliti, A. (2018). Mind the trap: large-scale field experiment shows that trappability is not a proxy for personality. Animal Behaviour, 142, 101-112.

Burger, J. R., Chesh, A. S., Castro, R. A., Tolhuysen, L. O., Torre, I., Ebensperger, L. A., \& Hayes, L. D. (2009). The influence of trap type on evaluating population structure of the semifossorial and social rodent Octodon degus. Acta Theriologica, 54(4), 311-320.

Burke, K. W., Wettlaufer, J., Beresford, D. V., \& Martin, P. (2020). Habitat use of co-occurring burying beetles (genus Nicrophorus) in southeastern Ontario. Canadian Journal of Zoology, (published on-line June 2020).

Camacho, C., Canal, D., \& Potti, J. (2017). Lifelong effects of trapping experience lead to agebiased sampling: lessons from a wild bird population. Animal Behaviour, 130, 133-139.

Carere, C., Caramaschi, D., \& Fawcett, T. W. (2010). Covariation between personalities and individual differences in coping with stress: converging evidence and hypotheses. Current Zoology, 56(6), 728-740.

Carroll, R. J., \& Schneider, H. (1985). A note on Levene's tests for equality of variances.

Statistics \& Probability Letters, 3(4), 191-194.

Carter, A. J., Heinsohn, R., Goldizen, A. W., \& Biro, P. A. (2012). Boldness, trappability and sampling bias in wild lizards. Animal Behaviour, 83(4), 1051-1058.

Clark, C. W. (1994). Antipredator behavior and the asset-protection principle. Behavioral Ecology, 5(2), 159-170.

Clarke, J., Manly, B., Kerry, K., Gardner, H., Franchi, E., Corsolini, S., \& Focardi, S. (1998).

Sex differences in Adélie penguin foraging strategies. Polar Biology, 20(4), 248-258.

Cockrem, J. F. (2007). Stress, corticosterone responses and avian personalities. Journal of Ornithology, 148(2), 169-178.

Peer) reviewing PDF | (2020:03:46448:1:1:NEW 28 Jul 2020) 
573 Cockrem, J. F. (2013). Individual variation in glucocorticoid stress responses in animals.

574 General and Comparative Endocrinology, 181, 45-58.

575

576 Cutler, D. R., Edwards Jr, T. C., Beard, K. H., Cutler, A., Hess, K. T., Gibson, J., \& Lawler, J. J.

577 (2007). Random forests for classification in ecology. Ecology, 88(11), 2783-2792.

578

579 d'Entremont, K., Minich Zitske, L., Gladwell, A., Elliott, N., Mauck, R., \& Ronconi, R. (2020).

580 Breeding population decline and associations with nest site use of Leach's Storm-Petrels on Kent

581 Island, New Brunswick from 2001 to 2018. Avian Conservation and Ecology, 15(1), 11.

582

583 Devost, I., Jones, T. B., Cauchoix, M., Montreuil-Spencer, C., \& Morand-Ferron, J. (2016).

584 Personality does not predict social dominance in wild groups of black-capped chickadees.

585 Animal Behaviour, 122, 67-76.

586

587

DeVries, M. S., Winters, C. P., \& Jawor, J. M. (2012). Testosterone elevation and response to

588 gonadotropin-releasing hormone challenge by male Northern Cardinals (Cardinalis cardinalis)

589 following aggressive behavior. Hormones and Behavior, 62(1), 99-105.

590

591

Drent, P. J., Verbeek, M. E., \& Boon, A. (1996). Exploration, aggressive behaviour and

592 dominance in pair-wise confrontations of juvenile male great tits. Behaviour, 133(11-12), 945-

593963.

594

595

Elekonich, M. M., \& Wingfield, J. C. (2000). Seasonality and hormonal control of territorial

596

597 aggression in female song sparrows (Passeriformes: Emberizidae: Melospiza melodia). Ethology, 106(6), 493-510.

598

599

Ficken, M. S., Weise, C. M., \& Popp, J. W. (1990). Dominance rank and resource access in

600 winter flocks of black-capped chickadees. The Wilson Bulletin, 623-633.

601

602

Fletcher, Q. E., \& Boonstra, R. (2006). Impact of live trapping on the stress response of the

603 meadow vole (Microtus pennsylvanicus). Journal of Zoology, 270(3), 473-478.

604

605 Foote, J. R., D. J. Mennill, L. M. Ratcliffe, and S. M. Smith (2010). Black-capped Chickadee

606 (Poecile atricapillus), version 2.0. In The Birds of North America (A. F. Poole, Editor). Cornell 607 Lab of Ornithology, Ithaca, NY, USA.

608

609 Fowler, J., Cohen, L., \& Jarvis, P. (2013). Practical statistics for field biology. John Wiley \& 610 Sons.

611 
612 Fox, R. A., Ladage, L. D., Roth II, T. C., \& Pravosudov, V. V. (2009). Behavioural profile

613 predicts dominance status in mountain chickadees, Poecile gambeli. Animal Behaviour, 77(6),

614 1441-1448.

615

616 Gabriel, P. O., \& Black, J. M. (2010). Behavioural syndromes in Steller's jays: the role of time 617 frames in the assessment of behavioural traits. Animal Behaviour, 80(4), 689-697.

618

619 Garamszegi, L. Z., Eens, M., \& Török, J. (2009). Behavioural syndromes and trappability in

620 free-living collared flycatchers, Ficedula albicollis. Animal Behaviour, 77(4), 803-812.

621

622 Garamszegi, L. Z., Markó, G., Szász, E., Zsebők, S., Azcárate, M., Herczeg, G., \& Török, J.

623 (2015). Among-year variation in the repeatability, within-and between-individual, and

624 phenotypic correlations of behaviors in a natural population. Behavioral Ecology and

625 Sociobiology, 69(12), 2005-2017.

626

627 Gorney, E., Clark, W. S., \& Yom-Tov, Y. (1999). A test of the condition-bias hypothesis yields

628 different results for two species of sparrowhawks (Accipiter). The Wilson Bulletin, 181-187.

629

630 Greggor, A. L., Thornton, A., \& Clayton, N. S. (2015). Neophobia is not only avoidance:

631 improving neophobia tests by combining cognition and ecology. Current Opinion in Behavioral

632 Sciences, 6, 82-89.

633

634 Griffiths, R., Double, M. C., Orr, K., \& Dawson, R. J. (1998). A DNA test to sex most birds.

635 Molecular Ecology, 7(8), 1071-1075.

636

637 Hegner, R. E. (1985). Dominance and anti-predator behaviour in blue tits (Parus caeruleus).

638 Animal Behaviour, 33(3), 762-768.

639

640 Holtmann, B., Lagisz, M., \& Nakagawa, S. (2017). Metabolic rates, and not hormone levels, are

641 a likely mediator of between-individual differences in behaviour: a meta-analysis. Functional

642 Ecology, 31(3), 685-696.

643

644 Hothorn, T., Hornik, K., \& Zeileis, A. (2006). Unbiased recursive partitioning: A conditional

645 inference framework. Journal of Computational and Graphical Statistics, 15(3), 651-674.

646

647 Hothorn, T., \& Zeileis, A. (2015). partykit: A modular toolkit for recursive partytioning in R.

648 The Journal of Machine Learning Research, 16(1), 3905-3909.

649 
650 Jimeno, B., Hau, M., \& Verhulst, S. (2017). Strong association between corticosterone levels and 651 temperature-dependent metabolic rate in individual zebra finches. Journal of Experimental

652 Biology, 220(23), 4426-4431.

653

654 Johnstone, C. P., Lill, A., \& Reina, R. D. (2014). Habitat loss, fragmentation and degradation 655 effects on small mammals: Analysis with conditional inference tree statistical modelling.

656 Biological Conservation, 176, 80-98.

657

658 Killen, S. S., Marras, S., \& McKenzie, D. J. (2011). Fuel, fasting, fear: routine metabolic rate

659 and food deprivation exert synergistic effects on risk-taking in individual juvenile European sea

660

661

662 bass. Journal of Animal Ecology, 80(5), 1024-1033.

Khonmee, J., Brown, J. L., Li, M. Y., Somgird, C., Boonprasert, K., Norkaew, T.,

664 Punyapornwithaya, V., Lee, W. M., \& Thitaram, C. (2019). Effect of time and temperature on stability of progestagens, testosterone and cortisol in Asian elephant blood stored with and

666

667 without anticoagulant. Conservation Physiology, 7(1), coz031.

668

Koolhaas, J. M., Korte, S. M., De Boer, S. F., Van Der Vegt, B. J., Van Reenen, C. G., Hopster, 669 H., De Jong, I. C., Ruis, M. A. W., \& Blokhuis, H. J. (1999). Coping styles in animals: current status in behavior and stress-physiology. Neuroscience \& Biobehavioral Reviews, 23(7), 925670935.

671

672 Krementz, D. G., \& Pendleton, G. W. (1990). Fat scoring: sources of variability. The Condor, 673 92(2), 500-507.

674

675 Landys, M. M., Ramenofsky, M., \& Wingfield, J. C. (2006). Actions of glucocorticoids at a 676 seasonal baseline as compared to stress-related levels in the regulation of periodic life processes. 677 General and Comparative Endocrinology, 148(2), 132-149.

678

679 Lohmus, M., Sundström, L. F., \& Moore, F. R. (2006). Non-invasive corticosterone treatment 680 changes foraging intensity in red-eyed vireos Vireo olivaceus. Journal of Avian Biology, 37(5), $681523-526$.

682

683

684 Lynn, S. E., \& Porter, A. J. (2008). Trapping initiates stress response in breeding and 685 non-breeding house sparrows Passer domesticus: Implications for using unmonitored traps in

685 field studies. Journal of Avian Biology, 39(1), 87-94.

687 Martins, T. L., Roberts, M. L., Giblin, I., Huxham, R., \& Evans, M. R. (2007). Speed of 688 exploration and risk-taking behavior are linked to corticosterone titres in zebra finches. 689 Hormones and Behavior, 52(4), 445-453. 
690

691 Maslo, B., Schlacher, T. A., Weston, M. A., Huijbers, C. M., Anderson, C., Gilby, B. L., Olds, 692 A. D., Connolly, R.M., \& Schoeman, D. S. (2016). Regional drivers of clutch loss reveal 693 important trade-offs for beach-nesting birds. PeerJ, 4, e2460.

694

695

696

697

698

699

700

701

702

703

704

705

706

707

708

709

710

711

712

713

714

715

716

717

718

719

720

721

722

723

724

725

726

727

728

729

McGlothlin J. W., Jawor J. M., Greives T. J., Casto J. M., Phillips, J. L., \& Ketterson, E. D. (2008). Hormones and honest signals: males with larger ornaments elevate testosterone more when challenged. Journal of Evolutionary Biology, 21(1), 39-48.

Michelangeli, M., Wong, B. B., \& Chapple, D. G. (2016). It'sa trap: sampling bias due to animal personality is not always inevitable. Behavioral Ecology, 27(1), 62-67.

Montreuil-Spencer, C., Schoenemann, K., Lendvai, Á. Z., \& Bonier, F. (2019). Winter corticosterone and body condition predict breeding investment in a nonmigratory bird. Behavioral Ecology, 30(6), 1642-1652.

Müller, D., Schröder, B., \& Müller, J. (2009). Modelling habitat selection of the cryptic Hazel Grouse Bonasa bonasia in a montane forest. Journal of Ornithology, 150(4), 717-732.

Nicolaus, M., Tinbergen, J. M., Bouwman, K. M., Michler, S. P., Ubels, R., Both, C., Kempanaers, B. \& Dingemanse, N. J. (2012). Experimental evidence for adaptive personalities in a wild passerine bird. Proceedings of the Royal Society B: Biological Sciences, 279(1749), 4885-4892.

Niemelä, P. T., Lattenkamp, E. Z., \& Dingemanse, N. J. (2015). Personality-related survival and sampling bias in wild cricket nymphs. Behavioral Ecology, 26(3), 936-946.

Peig, J., \& Green, A. J. (2009). New perspectives for estimating body condition from mass/length data: the scaled mass index as an alternative method. Oikos, 118(12), 1883-1891.

Ratcliffe, L., Mennill, D. J., \& Schubert, K. A. (2007). Social dominance and fitness in blackcapped chickadees. In: Otter, K. A., ed. Ecology and Behavior of Chickadees and Titmice: An Integrated Approach. Oxford : Oxford University Press, 131-147.

Réale, D., Gallant, B. Y., Leblanc, M., \& Festa-Bianchet, M. (2000). Consistency of temperament in bighorn ewes and correlates with behaviour and life history. Animal Behaviour, $60(5), 589-597$.

Réale, D., Reader, S. M., Sol, D., McDougall, P. T., \& Dingemanse, N. J. (2007). Integrating animal temperament within ecology and evolution. Biological Reviews, 82(2), 291-318.

Peer) reviewing PDF | (2020:03:46448:1:1:NEW 28 Jul 2020) 
730

731

732

733

734

735

736

737

738

739

740

741

742

743

744

745

746

747

748

749

750

751

752

753

754

755

756

757

758

759

760

761

762

763

764

765

766

767

768

769

Regelmann, K., \& Curio, E. (1986). Why do great tit (Parus major) males defend their brood more than females do? Animal Behaviour, 34(4), 1206-1214.

Romero, L. M., \& Reed, J. M. (2005). Collecting baseline corticosterone samples in the field: is under 3 min good enough? Comparative Biochemistry and Physiology Part A: Molecular \& Integrative Physiology, 140(1), 73-79.

Ruckstuhl, K. E. (1998). Foraging behaviour and sexual segregation in bighorn sheep. Animal Behaviour, 56(1), 99-106.

Schneider, K. J. (1984). Dominance, predation, and optimal foraging in white-throated sparrow flocks. Ecology, 65(6), 1820-1827.

Schoenemann, K. L., \& Bonier, F. (2018). Repeatability of glucocorticoid hormones in vertebrates: a meta-analysis. PeerJ, 6, e4398.

Shedd, D. H. (1983). Seasonal variation in mobbing intensity in the Black-capped Chickadee. The Wilson Bulletin, 343-348.

Sih, A., Bell, A., \& Johnson, J. C. (2004). Behavioral syndromes: an ecological and evolutionary overview. Trends in Ecology \& Evolution, 19(7), 372-378.

Simons, M. J., Winney, I., Nakagawa, S., Burke, T., \& Schroeder, J. (2015). Limited catching bias in a wild population of birds with near-complete census information. Ecology and Evolution, 5(16), 3500-3506.

Smith, S. M. (1991). The black-capped chickadee: behavioral ecology and natural history. Ithaca: Cornell University Press.

Smith, G. P., Bronstein, J. L., \& Papaj, D. R. (2019). Sex differences in pollinator behavior: patterns across species and consequences for the mutualism. Journal of Animal Ecology, 88(7), 971-985.

Spence, J. R., \& Niemelä, J. K. (1994). Sampling carabid assemblages with pitfall traps: the madness and the method. The Canadian Entomologist, 126(3), 881-894.

Stokes, V. L. (2013). Trappability of introduced and native rodents in different trap types in coastal forests of south-eastern Australia. Australian Mammalogy, 35(1), 49-53.

Peer) reviewing PDF | (2020:03:46448:1:1:NEW 28 Jul 2020) 
770 Stuber, E. F., Araya-Ajoy, Y. G., Mathot, K. J., Mutzel, A., Nicolaus, M., Wijmenga, J. J.,

771 Mueller, J. C., \& Dingemanse, N. J. (2013). Slow explorers take less risk: a problem of

772 sampling bias in ecological studies. Behavioral Ecology, 24(5), 1092-1098.

773

774 Tuyttens, F. A. M., Macdonald, D. W., Delahay, R., Rogers, L. M., Mallinson, P. J., Donnelly, 775 C. A., \& Newman, C. (1999). Differences in trappability of European badgers Meles meles in 776 three populations in England. Journal of Applied Ecology, 36(6), 1051-1062.

777

778 van Oers, K., Drent, P. J., De Goede, P., \& Van Noordwijk, A. J. (2004). Realized heritability 779 and repeatability of risk-taking behaviour in relation to avian personalities. Proceedings of the 780 Royal Society of London. Series B: Biological Sciences, 271(1534), 65-73.

781

782

783

784

785

786

787

788

van Oort, H., Otter, K. A., Fort, K. T., \& McDonell, Z. (2007). Habitat, dominance, and the phenotypic quality of male Black-capped Chickadees. The Condor, 109(1), 88-96.

Wack, C. L., DuRant, S. E., Hopkins, W. A., Lovern, M. B., Feldhoff, R. C., \& Woodley, S. K. (2012). Elevated plasma corticosterone increases metabolic rate in a terrestrial salamander.

789

790

791

Comparative Biochemistry and Physiology Part A: Molecular \& Integrative Physiology, 161(2), $153-158$.

792

793

794

Wada, H. (2008). Glucocorticoids: mediators of vertebrate ontogenetic transitions. General and Comparative Endocrinology, 156(3), 441-453.

795

796

797

Weatherhead, P. J., \& Greenwood, H. (1981). Age and condition bias of decoy-trapped birds. Journal of Field Ornithology, 52(1), 10-15.

Williams, T. D. (2008). Individual variation in endocrine systems: moving beyond the 'tyranny 798 363(1497), 1687-1698.

799

800 Wilson, A. D., Binder, T. R., McGrath, K. P., Cooke, S. J., \& Godin, J. G. J. (2011). Capture 801 technique and fish personality: angling targets timid bluegill sunfish, Lepomis macrochirus.

802 Canadian Journal of Fisheries and Aquatic Sciences, 68(5), 749-757.

803

804 Zanette, L., \& Ratcliffe, L. M. (1994). Social rank influences conspicuous behaviour of black805 capped chickadees, Parus atricapillus. Animal Behaviour, 48(1), 119-127. 


\section{Table $\mathbf{1}$ (on next page)}

Summary statistics and results of conditional inference tree analysis of several traits in black-capped chickadees caught by mist net or walk-in trap. 
1 Table 1. Summary statistics and results of conditional inference tree analysis and Levene's test

2 of variances of several traits in black-capped chickadees caught by mist net or walk-in trap.

3 Significant differences are indicated in bold font.

\begin{tabular}{|c|c|c|c|c|c|}
\hline \multirow[t]{2}{*}{ Trait } & \multirow[t]{2}{*}{ Sample size ${ }^{1}$} & \multicolumn{2}{|c|}{ Mean value (std dev) } & \multirow[t]{2}{*}{$\begin{array}{c}\text { ctree } \\
p \text {-value }\end{array}$} & \multirow[t]{2}{*}{$\begin{array}{l}\text { Levene's } F \text {, } \\
p \text {-value }{ }^{3}\end{array}$} \\
\hline & & Mist net & Walk-in trap & & \\
\hline Sex & 28,27 & $16 \mathrm{~F}, 12 \mathrm{M}$ & $12 \mathrm{~F}, 15 \mathrm{M}$ & 1.00 & \\
\hline Initial corticosterone ${ }^{4}(\mathrm{ng} / \mathrm{ml})$ & 25,27 & $7.25(3.18)$ & $6.45(3.08)$ & 1.00 & $0.16,0.69$ \\
\hline $\begin{array}{l}\text { Stress-induced corticosterone } \\
(\mathrm{ng} / \mathrm{ml})\end{array}$ & 27,26 & $30.5(15.0)$ & $30.7(14.1)$ & 1.00 & $<0.01,0.98$ \\
\hline Mass (g) & 27,27 & $11.0(0.77)$ & $11.2(0.81)$ & 1.00 & $0.21,0.65$ \\
\hline Tarsus length (mm) & 28,27 & $19.2(0.58)$ & $19.4(0.58)$ & 0.89 & $0.10,0.75$ \\
\hline Wing length (mm) & 28,27 & $65.9(2.29)$ & $66.5(2.19)$ & 1.00 & $0.01,0.94$ \\
\hline Scaled mass index (g) & 27,27 & $11.1(0.69)$ & $11.1(0.53)$ & 1.00 & $0.76,0.39$ \\
\hline Fat score $(0-5)$ & 28,27 & $1.1(0.48)$ & $1.0(0.69)$ & 1.00 & $4.18,0.05$ \\
\hline $\begin{array}{l}\text { Number of feeder trips, control } \\
\text { trial }^{5}\end{array}$ & 18,22 & $36.6(37.5)$ & $42.1(46.9)$ & 1.00 & $0.12,0.73$ \\
\hline $\begin{array}{l}\text { Number of feeder trips, predator } \\
\text { trial }^{5}\end{array}$ & 18,22 & $24.9(29.9)$ & $19.8(32.6)$ & 1.00 & $0.14,0.71$ \\
\hline $\begin{array}{l}\text { Number of feeder trips, novel } \\
\text { object trial }^{5}\end{array}$ & 18,22 & $30.9(30.2)$ & $28.0(28.7)$ & 1.00 & $0.01,0.92$ \\
\hline $\begin{array}{l}\text { Mean duration of feeder trips, } \\
\text { control trial (seconds) })^{5}\end{array}$ & 18,22 & $1.2(0.64)$ & $1.0(0.59)$ & 1.00 & $0.79,0.38$ \\
\hline $\begin{array}{l}\text { Mean duration of feeder trips, } \\
\text { predator trial (seconds) })^{5}\end{array}$ & 18,22 & $0.9(0.45)$ & $1.1(0.79)$ & 1.00 & $3.11,0.09$ \\
\hline $\begin{array}{l}\text { Mean duration of feeder trips, } \\
\text { novel object trial (seconds) }\end{array}$ & 18,22 & $1.3(0.75)$ & $1.2(0.77)$ & 1.00 & $0.20,0.66$ \\
\hline $\begin{array}{l}\text { Scaled change in number of trips, } \\
\text { predator trial }^{6}\end{array}$ & 18,21 & $0.23(1.90)$ & $-0.30(0.90)$ & 1.00 & $1.06,0.31$ \\
\hline $\begin{array}{l}\text { Scaled change in number of trips, } \\
\text { novel object trial }{ }^{6}\end{array}$ & 18,21 & $0.75(1.75)$ & $-0.29(0.52)$ & 0.24 & $9.56,<0.01$ \\
\hline $\begin{array}{l}\text { Scaled change in mean duration } \\
\text { of trips, predator trial }{ }^{7}\end{array}$ & 18,21 & $-0.04(0.65)$ & $0.25(1.09)$ & 1.00 & 0.78 .0 .38 \\
\hline Scaled change in mean duration & 18,21 & $0.33(1.08)$ & $0.16(0.65)$ & 1.00 & $0.98,0.33$ \\
\hline
\end{tabular}


of trips, novel object trial ${ }^{7}$

4

$5 \quad{ }^{1}$ Sample size is reported for mist nets and walk-in traps, respectively.

$6 \quad{ }^{2} p$-values are derived from conditional inference tree analysis using the command ctree in the partykit

7 package in $\mathrm{R}$.

$8{ }^{3} F$ statistics and $p$-values derived from Levene's tests comparing variances from the median among

9 capture methods, degrees of freedom $=1$.

$10{ }^{4}$ Raw values for initial corticosterone are shown, but residual corticosterone, controlling for a relationship

11 with sampling time, was analyzed. See main text for details.

$12{ }^{5}$ Number and duration are raw values for the number of times an individual was logged as visiting the

13 RFID feeder, or the mean duration of each trip, estimated as the total duration of time the bird was

14 detected on the feeder perch divided by number of trips during each 2-hour trial.

$15{ }^{6}$ Scaled change in number of trips to the RFID feeder calculated for each individual as: (number of visits

16 during the stimulus trial - number of visits during the pre-trial control period) / (number of visits during

17 the pre-trial control period).

$18{ }^{7}$ Scaled change in duration of time spent at the RFID feeder calculated for each individual as: (mean

19 duration of trips during the stimulus trial - mean duration of trips during the pre-trial control period) /

20 (mean duration of trips during the pre-trial control period). 


\section{Figure 1}

Morphological measurements of black-capped chickadees did not differ between individuals captured in mist nets or walk-in traps.

Points represent individual measurements (circles $=$ female, triangles $=$ male) and are jittered along the $x$-axis for ease of visualization. Horizontal lines in each boxplot represent the median, with the extent of boxes representing the 25th to 75th percentile of the data, and whiskers representing 1.5 inter-quartile ranges. See Table 1 for statistical support. 

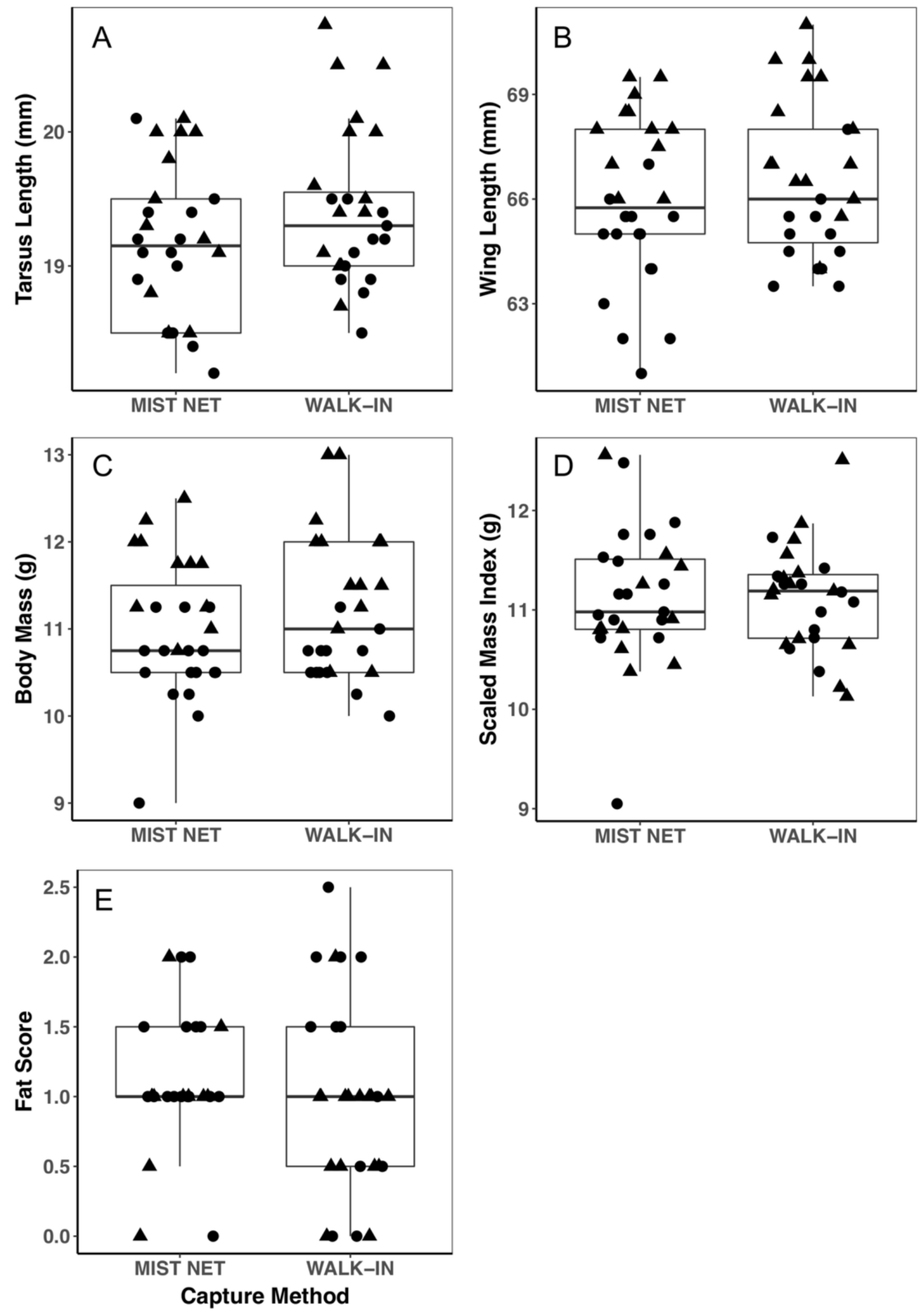

Peer) reviewing PDF | (2020:03:46448:1:1:NEW 28 Jul 2020) 
Figure 2

Corticosterone concentrations did not differ among black-capped chickadees captured in mist nets or walk-in traps.

Points represent individual measurements (circles $=$ female, triangles $=$ male) and are jittered along the $\mathrm{x}$-axis for ease of visualization. Panel A shows initial corticosterone measured as quickly as possible following capture, and panel B shows corticosterone measured 30 minutes after capture. Analyses of initial corticosterone controlled for timing of initial sample, but uncorrected values are shown here. Horizontal lines in each boxplot represent the median, with the extent of boxes representing the 25th to 75th percentile of the data, and whiskers representing 1.5 inter-quartile ranges. See Table 1 for statistical support.

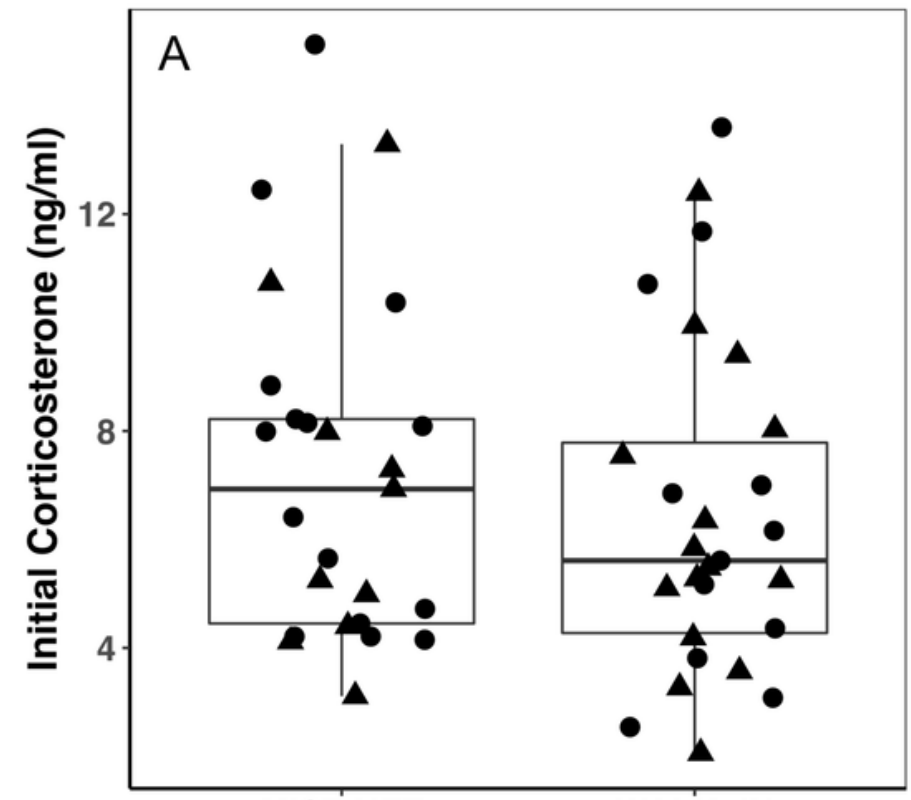

MIST NET
WALK-IN

Capture Method

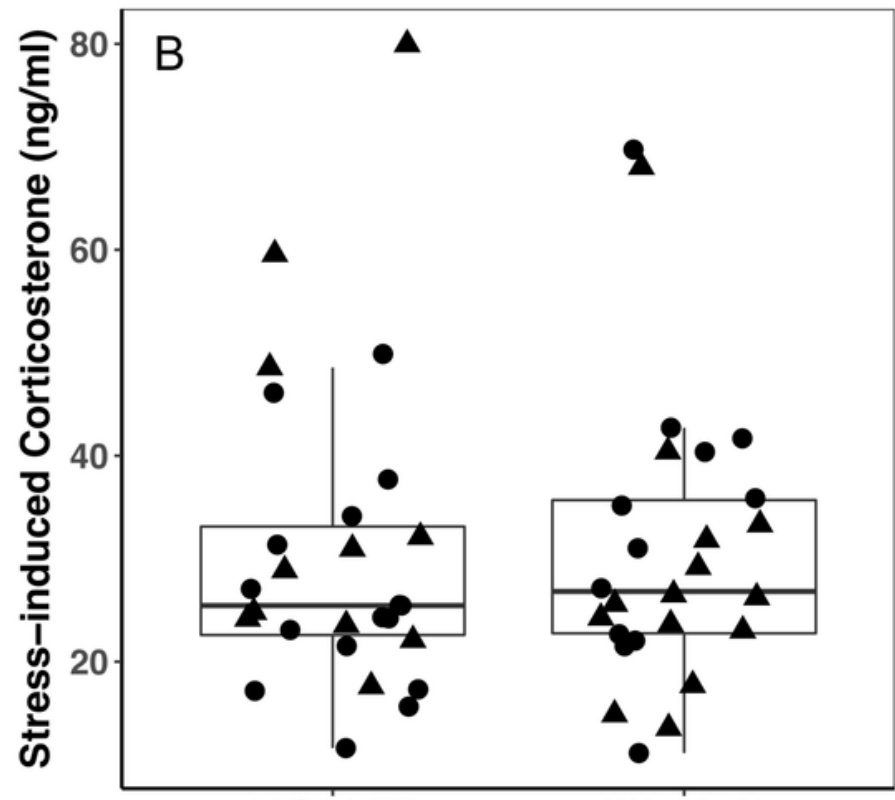

MIST NET

WALK-IN

Capture Method 


\section{Figure 3}

Behavioral responses to a model predator $(A \& C)$ and novel object $(B \& D)$ did not differ among black-capped chickadees captured in mist nets or walk-in traps.

Points represent individual measurements (circles $=$ female, triangles $=$ male) and are jittered along the $x$-axis for ease of visualization. Panels $A \& B$ show change in the number of trips recorded to a bird feeder equipped with a radio-frequency identification (RFID) receiver, scaled relative to the number of trips each individual made during a control trial of the same length (see main text for details). Panels $C \& D$ show change in the mean duration of trips to the RFID bird feeder, scaled relative to the mean duration of trips to the feeder during the control trial. Negative values represent a reduction of trips to or duration of time spent at the feeder, positive values represent an increase, and zeroes reflect no change, relative to behavior during a control trial. Horizontal lines in each boxplot represent the median, with the extent of boxes representing the 25th to 75th percentile of the data, and whiskers representing 1.5 inter-quartile ranges. See Table 1 for statistical support. 

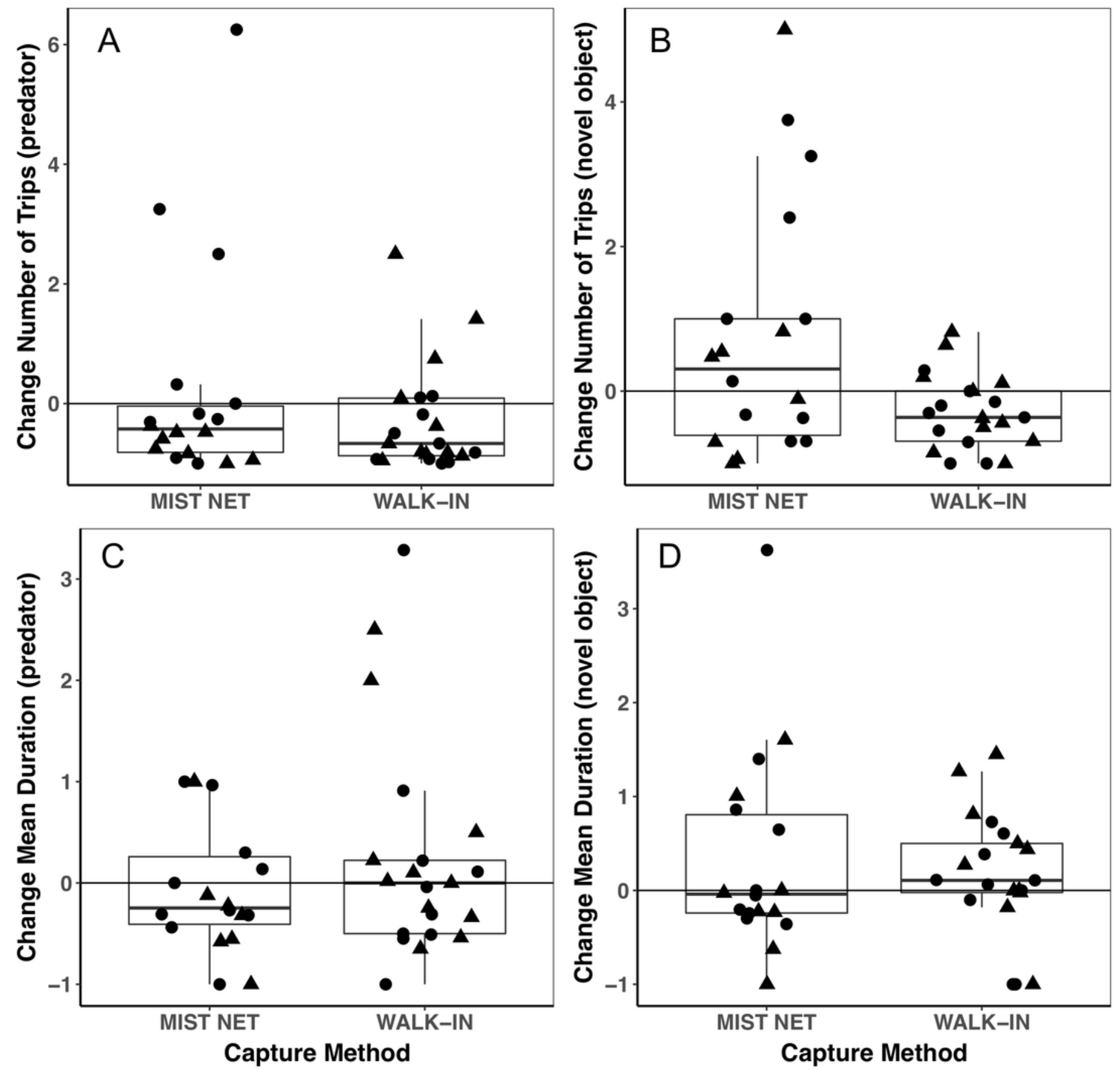